18.X-05 PORTABILITY AND MACHINE SPECIFICITY: A. DICHOTOMY FOR SOFTWARE PACKAGES.

S.R. Hall, Crystallography Centre, University of Western Australia, Nedlands 6009 , Australia.

Software packages are widely used in crystallography for reasons of convenience, economics and know-how. Rapid changes in computer technology, and the relative costs of computer time and manpower, have offset the advantages of developing efficient machine-specific software. Distributed packages place particular emphasis on the need for software portability. unfortunately with existing packages portability has often been achieved at the cost of computational efficiency.

This is because portability and machine specificity have been treated as mutually exclusive properties. The FORTRAN language provides limited options for resolving this problem. In contrast the "preprocessor" languages provide for both portability and machine specificity through the use of 'macros'. The application of the RATMAC preprocessor to the XTAL package (Hall, Munn a Stewart, Acta Cryst. A36, 979) will be outlined.

In conjunction with portability there is an increasing need for an integrated approach to the full spectrum of crystallographic problems. Crystal structure calculations on macromolecules and metals are similar in many respects except for the nature of the data. The XTAL approach to portable data management, through the use of contiguous data storage, dynamic memory allocation and directory addressable archival files, will be discussed.

18. X-06 FORTRAN COMPATIBILITY WITHOUT PREPROCESSORS. By George M. Shelarick, Anorg. Chemisches Institut der Universitüt

Tammannstraße 4, D3400 Göttingen, Fed. Rep. Of Germany .

It is possible to write FORTRAN programs which are both transportable and efficient, provided that certain rules are obeyed. The author will describe his experience with a simple program for crystallographic data reduction, structure solution and refinement (SHELX), which has been installed on about 250 computers representing all major makes, in many cases without changing a single FORTRAN statement.

SHELX is entirely written in a very simple subset of FORTRAN, similar to PIGIN FORTRAN described by stewart and Hall. Many problems affecting portability are avoided by NEVER using EQUIVALENCE, BACKSPACE, ENTRY, logical, double precision or complex variables, multiple dimension arrays, and subscripts other than 'I' or 'Itconstant'. Subroutines are used sparingly and $I / O$ is kept simple and buffered. A FORTRAN decoding routine enables free-format but machine-independent user input. Data are stored dynamically in a large one-dimensional array, which can easily be redimensioned to create small and large versions of the program. Sort-merge, direct methods and Fourier routines automatically make more use of scratch disc if less memory is available. Overlay may be used but is not essential; segmentation is also possible.
18.X-07 COMPUTER NETWORKS AND CRYSTALLOGRAPHY. By G. C. Bassi Département de Recherde Grenoble, 85x, 38041 Grenoble, France.

The needs for connections between computers of different origins and sizes have to be covered at various scales (local, national, international) in order to provide easy accesses to remote computing facilities and/or highly specialized Data Banks. The systems of Data Communications Networks, available now or in the near future, are supposed to provide such a service to users that must remain unaware of the complexity in transmission procedures. We shall look at various public and private networks: the access to these networks is described in terms of physical connections and protocols; the message transmission depending on the nature of the network, we give some ideas on international standard protocols (such as X25) for large scale networks, and specifications for local ones (such as ETHERNET). Some ideas on possible use of networks in the crystallographic field will be given: Data Eanks, highly specialized programs and systems, commercial services ...

18.1-01 INDEXING ASYMMETRICAL LAUE PHOTOGRAPHS BY MINICOMPUTER. By H. V. Hart and E. A. Rietman, Department of Chemistry, University of North Carolina at Wilmington, Wilmington, N. C. 28406 , U. S. A.

Recent computer solutions to the problem of indexing asymmetrical Laue photographs have been limited to maximum Miller indices of about 3 and a maximum number of reflections of about 10 and have required large amounts of time on a large computer (Ploc, J. Appl. Cryst. (1978), 11, 713). A more efficient algorithm has been programmed in BASIC for use with the Hewilett-Packard 2000/Access System, a 32 user time-shared minicomputer with $64 \mathrm{~K}$ words of core memory. The programs will index symmetrical or asymmetrical (no photograph synmetry is used), transmission or back-reflection Laue patterns of any crystal. Computational steps are:

(1) Spot coordinates are reduced to film coordinates of the reflecting plane normals with the equations of Bernalte (Acta Cryst. (1965), 19, 916), from which direction cosines of major zone axes are computed by a linear least-squares method. [The reflecting plane normals in a zone are coplanar and therefore intersect the film on a straight line. The zone axis is the normal to the crystal plane which intersects the film plane in this straight line.] Experimental interaxial angles are computed from the dot product of the zone axis direction cosines.

(2) Zone indices are determined (before Miller indices) by a trial-and-error search of interaxial angles computed from a master file of zone indices and orthogonal direction cosines prepared for each substance from its unit cell parameters.

(3) The zone lav is used to determine the Miller indices of spots at the intersections of the major 
zones on the film.

(4) Other spots are indexed by a trial-and-error search of interplanar angles within each zone separately, with the indexed spots from (3) as starting points.

The use of short programs (Iess than 2560 words each) and extensive data files minimizes core requirements so that the programs could be used with a laboratory microcomputer with aporopriate disc storage. Over 25 spots on each of several dozen laue photographs of calcite (trigonal) have been successfully indexed. In addition, the programs have been checked with Ploc's data for $a-2 r$ (hexagonal) with identical results, and with computer plots of indexed back-reflection. patterns of $\mathrm{Cu}$ (cubic), B-Sn (tetragonal), $\mathrm{Ga}$ forthohombic), and $\alpha-P_{u}$ (monoclinic, also as "triclinic") from Preuss et al. (Laue Atlas, N. Y., Wiley and Sons, 1974). Coordinates of $11-15$ intense reflections from each of the computer plots were entered as "data," and the published Miller indices were all correctly redetermined. Maximun Miller and zone indices of 20 and 8 , respectively, have teen found in calcite. Average interplanar and interaxial angular errors are about $0.1^{\circ}$ for carefully read and calibrated films or about $0.5^{\circ}$ for the published computer plots. Over 30 spots on a single film can be unambiguously indexed by a person with minimal crystallographic experience using these programs.

18.1-02 IDENTIFICATTON OF THE METRIC SYMMETRY OF A LATTICE BY FINDING ITS EVEN-ORDER SYMMETRY AXES By $\underline{Y}$. Le Page, Chemistry Division, M12-BG. NRC, OTTAWA, CANADA, KIA ORg

The present approach is based on the identification of even-order symmetry axes (EOSA) according to the following three points: (1) A row [h] is an EOSA of a lattice if and only if there is a reciprocal row [p*] such that $h \times \mathrm{p}^{*}=0$ with $\mathrm{h}$. $\mathrm{p}^{*}=1$ or 2 ; (2) If the lattice is referred to its 3 shortest non-coplanar translations, the moduli of the Miller indices of [h] and $\left[p^{*}\right]$ cannot be larger than 2 ; (3). A lattice symetry is uniquely determined by the number and distribution in space of its EOSA.

The first two points allow an exhaustive. list of the EOSA in the lattice to be made. Comparison of the number and distribution of EOSA in space with those possible allows the lattice symmetry to be identified according to point 3. By this process, the lattice is placed in a conventional orientation and the selection of the edges of the conventional cell is guided by the coincidence of lattice rows with pre-determined symetry axes.

Some advantages over the traditional approach sumarized in International Tables (1969) Vol. 1 pp. 530-535 are: The recognition of the lattice symetry can be accomplished by one logical process rather than 44 branches; seudo symmetry in the primitive cell can be liandled in a straightforward way; A Buerger reduced cell rather than the Niggli reduced cell is required; No metric considerations are built into the recognition of the lattice symmetry. Metric conventions in orthorhombic, monoclinic and triclinic are handled separately.

The program tuns on PDP8-E, PDP11 and CDC 7400 computers and has been inserted as an overlay in the NRC Fortran diffractometer program.
18.1-03

\section{INTELLIGENCE ARTIFICIELLE ET} MESURE DE PIC

par

M. Tournarie

DphG-PSRM, CEA, B.P.n०2, $91191 \mathrm{Gi}$ sur Yvette, France

On sait ${ }^{[1]}$ que chaque observation permet l'affinement imédiat de toutes les variables descriptives du phénomène physique qui lui a donné naissance. Cette remarque conduit à la construction d'un algorithme genera1[3] permettant à la fois le traitement des données experimentales et le choix des conditions d'acquisition suboptimales. I'emploi de cet algorithme évite de consacrer beaucoup de temps aux observations peu efficaces.

Pour optimiser il faut définir un critère qu'on cherchera à rendre extrêmal. Le critère choisi est le gain d'information apporte par chaque observation sur une combinaison tinéaire des inconnues. On aboutit alors à l'algorithme suivant.

Ayant choisi la combinaison linéaire $\langle c \mid x\rangle$ dont on veut optimiser la mesure ayant les valeurs $\mid z>$ a priori de $|x\rangle$ et la matrice d'erreur $E$ relative à ces estimations.

$1^{\circ}$ ) Pour chaque observation possible a) calculer son espérance a et l'espérance de son vecteur gradient a par rapport aux inconnues estimees $a=\operatorname{Esp}(y \| z>)$

b) calculer pour le temps d'observation t la quanti-

$$
Y=\frac{T}{q a+\tau<a|E| a>} q \text { : quantum unité }
$$

c) determiner l'observation qui fait décroitre le plus vite l'écart type sur $\langle c \mid x\rangle:$ c'est l'observation qui présente le $\langle c|E| c\rangle u=\gamma\langle c|E| a\rangle^{2}$ maximum.

$2^{\circ}$ ) Effectuer cette observation.

$\left.3^{\circ}\right)$ Calculer les notvelles estimations $|z\rangle$ des inconnues et leur matrice d'erreur $E$ selon la formule de Iéestimation linéaire [1].

$$
\begin{aligned}
& \left.|z>+| z>+\frac{\mathrm{y}-\mathrm{a}}{\mathrm{q} a+\mathrm{I}\langle\mathrm{a}|\mathrm{E}| \mathrm{a}\rangle}|\mathrm{E}| \mathrm{a}\right\rangle \\
& \mathrm{E}+\mathrm{E}-\frac{\mathrm{I}}{\mathrm{qa}+\mathrm{\tau}\langle\mathrm{a}|\mathrm{z}| \mathrm{a}\rangle} \mathrm{E}|\mathrm{a}\rangle\langle\mathrm{a}|\mathrm{E}|
\end{aligned}
$$

$\left.4^{\circ}\right)$ Si la variation de $|z\rangle$ est déraisonnable ou aboutit à des valeurs de $|z\rangle$ déraisonnables, effectuer une réestimation non linéaire des inconnues [2]

$\left.5^{\circ}\right)$ Si la précision obtenue n'est pas suffisante et si la durée totale acceptée pour l'ensemble des observations n'est pas épuisée revenir en $1^{\circ}$ )

$\left.6^{\circ}\right)$ Fin

Une application à la recherche, la détermination et l'affinement des caractéristiques (intensite, position, largeur, dissymétrie) de pic est présentée.

1 TOURNARIE M. (1969), Ann. Inst. H. Poincare 5 , $\mathrm{n}^{\circ} 1, \mathrm{~B}, 49-67$

2 TOURNARIE $M$. (1969) J. Physique 30, $\mathrm{N}^{\circ} 10,737-751$

3 TOURNARIE M. (1978), Cybemetica XXI, 3, 227-262 